\title{
GENETIC MARKERS IN THE ATOMIC BOMB SURVIVORS AND THEIR CHILDREN - HIROSHIMA AND NAGASAKI
}

\author{
Howard B. Hamilton* \\ Clinical Laboratories, Radiation Effects Research \\ Foundation, Hiroshima 730, Japan
}

Genetic Markers have played an important role in RERF surveys of the populations of Hiroshima and Nagasaki, in the search for radiation-induced damage to the A-bomb survivors and their children. An early basic program at RERF was, and continues to be, a large scale attempt to assess genetic damage in the children of A-bomb survivors, hereafter referred to as the $F_{1}$ generation. For the first studies, 35 years ago, in lieu of genetic markers in the blood, relatively insensitive morphological indicators were used: still-births, viability at birth, gross malformations, neonatal death and others-in short "untoward pregnancy outcomes" were taken as signalling possible genetic damage in the $F_{1}$. As described elsewhere (Neel and Schull, 1956), no significant increase in untoward pregnancy outcomes was observed that could be related to radiation exposure of the parents. In addition, the $F_{1}$ cohort has been monitored continuously for mortality, without evidence of a significant effect of parental exposure on the frequency of death among the offspring (Neel et al., 1974).

Another screening strategy was to search for so-called "sentinel phenotypes" (aside from dominant lethals), which would include anomalies such as Down's, Klinefelter's and Turner's syndromes. No excess of Down's syndrome has been found among the $F_{1}$ (Schull and Neel, 1962). In a survey of over 4,000 male high school students, staining buccal smears for sex chromatin, three hitherto unsuspected cases of Klinefelter's syndrome were found, all children of non-exposed parents. No sex chromatin anomalies were found among 2,660 females of the same age (Omori et al., 1969).

These early programs set the stage for studies of the $F_{1}$ now in progress. With the development of cytogenetics techniques on the one hand, and electrophoretic methods for identifying variant protein molecules on the other, new dimensions

* Chief, Clinical Laboratories, Radiation Effects Research Foundation (RERF), successor organization to ABCC, the Atomic Bomb Casualty Commission. RERF was established in Aprial 1975 as a private non-profit Japanese Foundation, supported equally by the Government of Japan through the Ministry of Health and Welfare, and the Government of the United States of America through the National Academy of Sciences under contract with the Department of Energy. 
were added to the search for mutations in the $F_{1}$, and the use of genetic markers became a corner-stone of the program.

Recently Awa and his colleagues (Awa et al., 1981) reported that in their cytogenetic study of almost $11,000 \mathrm{~F}_{1}$, the "frequencies of cytogenetically abnormal children of A-bomb exposed parents are not significantly different from those born to non-exposed parents."

The Biochemical Genetics Study (BGS) now searches for possible mutations in the $F_{1}$ (see Neel et al., 1980 for details) by electrophoretically screening the population for rare structural protein variants in 30 systems, and by kinetic analysis for enzyme deficiency variants using 10 systems. In over 400,000 locus tests of children of the exposed, two putative new structural (electrophoretic) mutations have been encountered, and none in almost 300,000 tests among the controls. In addition, in these electrophoretic studies, 700 rare variants have been found among. which over 500 are also present in one of the parents, where family studies were possible. Rare enzyme activity deficiency variants (where enzyme activity is not more than $66 \%$ of normal) occur at an average frequency of 2.9 per 1,000 determinations in Hiroshima, in over 12,000 enzyme studies, similar to the frequency of rare electrophoretic variants. So far no mutations of deficiency variants have been encountered (Satoh et al., 1981).

Some of the data described above can be used to generate crude estimates of the minimum gametic doubling dose, as recently reported elsewhere (Schull et al., 1981). There are insufficient biochemical data for this purpose, but those from the untoward pregnancy outcomes, childhood survival and chromosome aneuploidy yield three different, but to some extent overlapping estimates (Table 1). An unweighted average of the three is $258 \mathrm{rem}$ for acute radiation exposure. A weighted

Table 1. Estimates for gametic doubling dose in man based on genetic studies at RERF.

\begin{tabular}{lcc}
\hline & Number studied & $\begin{array}{c}\text { Gametic doubling } \\
\text { dose REM* }\end{array}$ \\
\hline Untoward pregnancy outcomes & 70,082 & 69 \\
Childhood mortality & 63,817 & 171 \\
Chromosome aneuploidy & 10,820 & 535 \\
Arithmetic average & & 258 \\
Weighted average & & 139 \\
\hline
\end{tabular}

* The doubling doses are computed from regression coefficients which, though not statistically significant and with large variances attached to them, are in the direction expected, that is, positive for a radiation effect. The standard deviation of each estimate is larger than the estimate itself. That for the weighted average, calculated from the inverse of the variance for each estimate is about 157 . See Schull et al., 1981a for details. Note also that other recent papers (Schull et al., 1981; Satoh et al., 1981) report doubling doses, differing in some instances from those shown herc, accounted for by the fact that though the population bases are the same, the results are slightly modified by the addition of more recent data. 
mean, taking into account disparities in population sizes of the three studies is 139 rem. It must be borne in mind that these estimates are crude tentative approximations of the gametic doubling dose, with large variances attached to them. Moreover, they certainly will be revised when reassessment of the doses is completed (Loewe and Mendelssohn, 1981). Nonetheless, these estimates are notable for having been derived, for the first time, from human data instead of by extrapolation from non-human species.

Turning now to the health surveillance of the exposed populations of Hiroshima and Nagasaki (which includes sex and age-matched non-exposed controls) known as the Adult Health Study (AHS), it is important to note that the members of these groups are ambulatory, essentially healthy individuals who visit our clinics regularly on a voluntary basis ence every two years. Over the course of these cyclic visits, a variety of surveys involving genetic markers in the blood have contributed greatly to our knowledge of the genetic characteristics of these populations. The one survey yielding data related to exposure comes from the cytogenetic studies of the exposed by Awa and his colleagues, who have demonstrated by now the well-known relationship between dose and chromosome aberrations in the peripheral blood lymphocytes, present even many years after exposure. The response is linear for Hiroshima and appears to be curvilinear for Nagasaki, though current dose reassessments will require further careful analysis of the data. So far, there are no discernible effects on the health of the individuals who are harboring these chromosomal aberrations (Awa et al., 1978).

Radiation effects aside, the cytogenetic survey of this group, as well as of the $F_{1}$, using various staining methods (C-banding, etc.), has demonstrated the presence of a variety of normally occurring heteromorphisms, such as double satellites, increased heterochromatic C-band variants, particularly in chromosomes 1, 9, and 16, that are known to be inherited chromosomal variants. A relationship to radiation exposure has not been demonstrated.

Biochemical markers in the blood have been used extensively in the Health Surveillance Program of ABCC-RERF. Early surveys focused on single rare genetic traits, such as identifying heterozygous carriers for the rare gene for acatalasia or on detecting rare mutant hemoglobins. For the former, 11 of 13,000 screened were heterozygous for the acatalasia gene (Hamilton et al., 1961) and for the latter three mutant hemoglobins were found, two for the first time in Japan, and one of these, $\mathrm{Hb}$ Hiroshima with altered physicochemical characteristics (high oxygen affinity and reduced Bohr effect) which provided further support for the model of Perutz and others to explain the complicated structure-function relationships of normal hemoglobin (Perutz et al., 1971).

The Biochemical Genetics Study described earlier for the $F_{1}$ was first applied to the AHS as a pilot investigation, examining electrophoretically the red cells and sera from about 3,000 individuals for rare variants in 22 protein systems. The average frequency of rare variants was somewhat over 2 per 1,000 examinations, 
taking note of the fact that some loci contributed disproportionately large numbers of variants (vzi: GPI, $\left.P G M_{1}, T F\right)$ while others were monomorphic $\left(C A_{2}, P G M_{2}\right.$, $A K_{2}$, others). For a pair of homologous proteins, phosphoglucomutase ${ }_{1}$ and phosphoglucomutase $2\left(\mathrm{PGM}_{1}\right.$ and $\left.\mathrm{PGM}_{2}\right)$, the difference in overall frequency and number of different kinds of variants was highly significant $(p<0.001)$, and a test for differences in relative mutation rates between the two loci appears to indicate a higher mutation rate for the structural gene for $\mathrm{PGM}_{1}$ than for $\mathrm{PGM}_{2}$ (Neel et al., 1978).

At two loci, $P G M_{1}$ and glucosephosphate isomerase (GPI), significant intercity differences were found: there are not only more variants in Nagasaki, but more types of variants, e.g.: for GPI4 ${ }_{\mathrm{HIR} 1}$, there were 15 in Nagasaki and only 11 in Hiroshima in a population twice as large; for a rare $\mathrm{PGM}_{1} 3$ type, 6 persons had the variant in Nagasaki, but none in Hiroshima. The equal distribution of $P G M_{1}{ }^{7}$ in Hiroshima and Nagasaki argues for a gene of some antiquity whereas that for GPI4 $4_{\text {HrR }}$ may have arisen later, judging from its very unequal distribution in the two cities.

A comparison between the Japanese population and a British Caucasoid population where the same laboratory methods were used, show significantly higher frequencies of variants for two systems, $\mathrm{PGM}_{1}$ and GPI, when tested by a chisquare method, but none when a theta statistic testing for differences in relative mutation rates is applied. We may be suspicious that there might be a difference in mutation rates in the two populations at these loci, but further refinements in laboratory approaches are necessary: amino acid sequencing, enzyme kinetic studies, and thermostability characteristics, among others.

Electrophoretic techniques combined with thermostability studies, using rapid kinetic analysis demonstrated "hidden" genetic heterogeneity in the PGI system, where 20 unrelated individuals with an identical electromorph variant $\left(G P I I-4_{\mathrm{HIR} 2}\right)$ could be grouped into three sub-classes according to heat stability characteristics (Satoh and Mohrenweiser, 1978). The traits are inherited. Such heterogeneity is well known among human hemoglobins ascertained by much more laborious methods.

Data from blood typing of over 11,000 of the AHS for several major blood groups $\left(\mathrm{A}_{1} \mathrm{~A}_{2} \mathrm{BO}, \mathrm{CDEce}, \mathrm{MNSs}, \mathrm{Kk}\right)$ have been used to obtain phenotype and gene frequencies. There are significant departures from Hardy-Weinberg expectation in the $A B O, R h$ and MNS systems $(p<0.001)$. For $A B O$, there is an excess of $\mathrm{A}_{2} \mathrm{~B}$ and a deficiency of $\mathrm{A}_{2}$ (Table 2). Among possible explanations (aside from typing errors, which have been excluded by retesting) may be the occurrence of the cis- $\mathrm{A}_{2} \mathrm{~B}$ chromosome as a 'fifth' locus in the system due to unequal crossing over, or of a bifunctional transferase system arising from a structural gene mutation. Both are susceptible to testing by elegant biochemical analyses of fucosyltransferase activity in the plasma (Yoshida et al., 1980). The disequilibrium in our data disappear when the A subgroups are combined; comparison with frequencies from other Japanese sources (Fujita et al. 1978) then shows no substantial differences (Table 3: $\mathrm{A}_{1} \mathrm{~A}_{2}$ data apparently are not available for other areas of Japan). 
Table 2. ABO blood group phenotypes-Hiroshima.

\begin{tabular}{crrrrrr}
\hline \multirow{2}{*}{ Phenotype } & \multicolumn{2}{c}{ Number } & \multicolumn{2}{c}{ Proportion } & $\chi^{2}$ \\
\cline { 2 - 3 } & Observed & Expected & & Observed & Expected & \\
\hline $\mathrm{A}_{1}$ & 3,794 & $3,799.8$ & & 0.4006 & 0.4012 & 0.0089 \\
$\mathrm{~A}_{2}$ & 10 & 22.0 & & 0.0011 & 0.0023 & 6.5105 \\
$\mathrm{~B}$ & 1,981 & $1,997.8$ & & 0.2092 & 0.2109 & 0.1408 \\
$\mathrm{~A}_{1} \mathrm{~B}$ & 956 & 949.0 & & 0.1009 & 0.1002 & 0.0529 \\
$\mathrm{~A}_{2} \mathrm{~B}$ & 19 & 7.0 & & 0.0020 & 0.0007 & 20.5637 \\
$\mathrm{O}$ & 2,711 & $2,695.5$ & & 0.2862 & 0.2846 & 0.0888 \\
\hline Total & 9,471 & $9,471.1$ & 1.0000 & 1.0000 & $27.3657^{*}$ \\
\hline
\end{tabular}

$* \mathrm{p}<0.001$

(Source: RERF WT-0679)

Table 3. ABO phenotype and gene frequencies Hiroshima-Nagasaki and all Japan compared.

\begin{tabular}{|c|c|c|c|c|}
\hline & \multicolumn{2}{|c|}{ Phenotypes (proportions) } & \multicolumn{2}{|c|}{ Gene frequency } \\
\hline & $\begin{array}{c}\text { Hiroshima } \\
\text { Nagasaki }\end{array}$ & All Japan* & $\begin{array}{c}\text { Hiroshima } \\
\text { Nagasaki }\end{array}$ & All Japan* \\
\hline $\mathrm{O}$ & .2806 & .2925 & .5287 & .5407 \\
\hline A & .4011 & .3865 & .2975 & .2833 \\
\hline $\mathrm{B}$ & .2126 & .2215 & .1733 & .1759 \\
\hline $\mathrm{AB}$ & .1049 & .0995 & & \\
\hline Number tested & & $4,465,349$ & 13,709 & \\
\hline
\end{tabular}

* Fujita et al., 1979.

In the much more complicated $\mathrm{Rh}$ system, there is an excess of $R h^{1}$ and $R h^{2}$ and a deficiency of $\mathrm{Rh}^{1} \mathrm{Rh}^{2}$, which might be partly ascribable to the presence of the -D-complex lacking antigens in the C and E series (Race and Sanger, 1975). We have some evidence suggesting the null allele may be present judging from a number of studies of parent-child trios where one parent is $R h^{1}$, the other $R h^{2}$ and the child has the phenotype of only one parent instead of the expected $R h^{1} R^{2}$, explicable, if the parent for whom the Rh type does not appear in the child, is heterozygous for the null complex.

In the MNSs system, departures from expectation are too complicated to describe here, save for an obvious excess of SS, whether combined with $M$ or $N$ and a deficiency of MN. At present there is no simple explanation for these discrepancies.

For the Kell-Cellano system, the frequency of the $\mathrm{K}-\mathrm{k}+$ phenotype in over 14,000 tests was 0.9997 ; no $K+k$ - examples have been found; one family with the 
$\mathrm{K}^{\circ}$ (Kell null) phenotype, the first in Japan, was encountered (Hamilton and Nakahara, 1971).

For future monitoring of our exposed populations and their offspring there is much to be done. It is a commonplace that each of us (save monozygotic twins) differ biochemically and therefore genetically, from one another in countless ways, a fact well demonstrated by earlier speakers in these meetings. With respect to the primary radiation effect in our exposed populations, carcinoma, we need to know all we can about genetic differences and, probably more important, about similarities, as a guide to understanding whatever the genetic basis of cancer may be. We are adding another dimension to the genetic characterization of our populations through immunogenetic techniques, such as HLA typing. Knowing as many of the genetic metrics as possible will be useful in the search for associations between diseases and genetic polymorphisms (haptoglobin types and anemia, blood groups and gastric carcinoma, phenylthiourea tasters and thyroid disease, for example); for tracing population migrations; in monitoring human populations for effects of exposure to environmental mutagens.

That we have failed to find genetic damage among the children of the exposed is reassuring. As has been repeatedly demonstrated in other species, radiation can cause genetic damage, but the extent, if any in the $F_{1}$ appears to be too small to be detected by current methods, even at the cellular and molecular level. Ideally, the entire genome should be characterized biochemically, a feat at present not possible. Approaches to this might be by sorting chromosomes by DNA content, producing a sort of an individual profile; or developing probes to search for mutations in the repeating "silent" (introns) portions of DNA. With the rapid development of molecular biological techniques, it may one day be possible to describe precisely the nature of the genetic changes, if any, that have occurred in the children of the exposed.

Acknowledgement This cursory review claims neither originality nor completeness, touching only on certain highlights of 35 years' endeavor. Many hands have contributed to the work herein presented, more than can be enumerated. I am particularly grateful for the highly valued help of colleagues in Japan, many friends of long-standing and members of this Society, without whose counsel this report would not have been possible.

\section{REFERENCES}

Awa, A.A., Sofuni, T., Honda, T., Itoh, M., Neriishi, S., and Otake, M. 1978. Relationship between the radiation dose and chromosome aberrations in atomic bomb survivors in Hiroshima and Nagasaki. Jpn. J. Rad. Res. 19: 126-140.

Awa, A.A., Honda, T., Neriishi, S., Shimba, H., Amano, T., and Hamilton, H.B. 1981. An interim report of the cytogenetic study of the offspring of atomic bomb survivors in Hiroshima and Nagasaki. Sixth International Congress of Human Genetics, Jerusalem, Israel, 13-19 Sept.

Fujita, Y., Tanimura, M., and Tanaka, K. 1978. The distribution of the ABO blood groups in Japan. Jpn. J. Human Genet. 23: 63-109. 
Hamilton, H.B., Neel, J.V., Kobara, T.Y., and Ozaki, K. 1961. The frequency in Japan of carriers of the rare "recessive" gene causing acatalasemia. J. Clin. Invest. 40: 2199-2208.

Hamilton, H.B., and Nakahara, Y. 1971. The rare Kell blood group phenotype $\mathrm{K}^{\circ}$ in a Japanese family. Vox Sang. 20: 24-28.

Loewe, W.W., and Mendelssohn, E. 1981. Revised dose estimates at Hiroshima and Nagasaki. Health Phys. 41: 663-666.

Neel, J.V., and Schull, W.J. 1956. The effect of Exposure to the Atomic Bombs on Pregnancy Terminations in Hiroshima and Nagasaki. Publ. 461, NAS-NRC, Washington, D.C.

Neel, J.V., Kato, H., and Schull, W.J. 1974. Mortality in children of atomic bomb survirors and controls. Genetics 76: 311-326.

Neel, J.V., Ueda, N., Satoh, C., Ferrell, R.E., Tanis, R.J., and Hamilton, H.B. 1978. The frequency in Japanese of genetic variants of 22 proteins. V. Summary and comparison with data on Caucasians from the British Isles. Ann. Hum. Genet., Lond. 41: 429-441.

Neel, J.V., Satoh, C., Hamilton, H.B., Otake, M., Goriki, K., Kageoka, T., Fujita, M., Neriishi, S., and Asakawa, J. 1980. Search for mutations affecting protein structure in children of atomic bomb survivors: a preliminary report. Proc. Natl. Acad. Sci. USA. 77: 4221-4225.

Omori, Y., Morrow, L.R., Ishimaru, T., and Johnson, K.G. 1969. A buccal smear survey for sex chromatin aberration in high school students, Hiroshima. Hiroshima J. Med. Sci. 18: 21-30.

Perutz, M.F., Del Pulsinelli, P., Ten Eyck, L., Kilmartin, J.V., Shibata, S., Iuchi, I., Miyaji, T., and Hamilton, H.B. 1971. Haemoglobin Hiroshima and the mechanism of the alkaline Bohr effect. Nature, New Biol. 232: 147-149.

Race, R.R., and Sanger, R. 1975. Blood Groups in Man. 6th Ed., Blackwell, Oxford.

Satoh, C., and Mohrenweiser, H.W. 1978. Genetic heterogeneity within an electromorphic phenotype of glucose phosphate isomerase in a Japanese population. Am. J. Hum. Genet. 43: 283292.

Satoh, C., Awa, A.A., Neel, J.V., Schull, W.J., Kato, H., Hamilton, H.B., Otake, M., and Goriki, K. 1981. Genetic effects of the atomic bombs. Sixth International Congress of Human Genetics, Jerusalem, Israel, 13-19 Sept.

Schull, W.J., and Neel, J.V. 1962. Maternal radiation and mongolism. Lancet i No. 7228: 537538, 10 Mar.

Schull, W.J., Otake, M., and Neel, J.V. 1981. Genetic effects of the atomic bombs: a reappraisal. Science 213: 1220-1227.

Schull, W.J., Neel, J.V., Otake, M., Awa, A.A., Satoh, C., and Hamilton, H.B. 1981a. Hiroshima and Nagasaki: Three and a half decades of genetic screening. Third International Congress of Mutagenesis. Tokyo, Japan, 21-24, Sept.

Yoshida, A., Yamaguchi, H., and Okubo, Y. 1980. Genetic mechanism of cis-AB inheritance. II. Cases associated with structural mutation of blood group glycosyltransferase. Am. J. Hum. Genet. 32: 645-650. 